\title{
Further Studies on the Interrelationship between Parathyroid Hormone and Vitamin D*
}

\author{
Claude Arnaud, Howard Rasmussen, $\dagger$ and Constantine Anast $\ddagger$ \\ (From the Department of Biochemistry, University of Pennsylvania School of Medicine, \\ Philadelphia, Pa., and the Department of Pediatrics, University of Missouri School \\ of Medicine, Columbia, Mo.)
}

Calcium homeostasis is achieved by the interplay of a number of humoral agents (1). Of central importance are the activities of parathyroid hormone (PTH) and of vitamin D. This was fully appreciated 35 years ago (2), but in spite of considerable effort, the nature of the relationship remains controversial. Recent opinion has varied from that of a complete dependence of hormone action upon the presence of vitamin D (3) to that of a complete independence of action $(4,5)$. In our initial studies of this problem, we concluded that in the absence of vitamin $\mathrm{D}$ a physiologic concentration of parathyroid hormone exerted its usual effect upon the renal excretion of phosphate but was unable to mobilize calcium from bone (6).

Since these studies were published, two groups of investigators have challenged our conclusions $(7,4)$. Harrison and Harrison reaffirmed their previous observations ( 7 ) and concluded, as they had before, that all of the actions of parathyroid hormone depended upon vitamin D. At the opposite extreme, Ney and associates concluded that all of the effects of parathyroid hormone are exerted in the D-deficient organism. These differences are difficult to explain. However, both studies differed from ours in several respects. In the study of Harrison and Harrison (7), no attempt was made to define or control the level of endogenous parathyroid hormone, although we found this

\footnotetext{
* Submitted for publication April 8, 1966; accepted September 7, 1966.

Presented in part at the 47th Annual Meeting of the Endocrine Society, June 1965.

Supported by grants from the National Institutes of Health (AM-09650, AM-09494-01, and AM-01351-08).

$\dagger$ Address requests for reprints to Dr. Howard Rasmussen, Dept. of Biochemistry, University of Pennsylvania School of Medicine, Philadelphia, $\mathrm{Pa}$.

$\ddagger$ Dept. of Pediatrics, University of Missouri, Columbia, Mo.
}

to be of prime importance (6). In the work done by Ney and co-workers a different species was employed, and the degree of $\mathrm{D}$ deficiency was assessed by different criteria (4). Nevertheless, both studies raised points that seemed worthy of further examination.

The development of a technique for study of the response of the conscious rat to the long-term perfusion of hormones (8) has allowed us to examine several aspects of this problem more directly. The experimental design permitted the exclusion of altered endogenous secretion of parathyroid hormone or thyrocalcitonin as variables. The results reaffirm our previous conclusion and explain, in large part, the previous disparity of opinion regarding the nature of the parathyroid hormone vitamin $\mathrm{D}$ interrelationship.

\section{Methods}

Vitamin D deficiency was produced in young growing Holtzman rats as previously described (9). Control animals received the same purified diet but were given $75 \mathrm{U}$ of vitamin $\mathrm{D}_{3}$ in cottonseed oil by oral intubation daily for the week before study. Urinary calcium and phosphate were measured simultaneously with a Technicon Autoanalyzer (6). Plasma calcium and phosphate were measured by the same means except for a manifold modification that allowed for a microdetermination on 50 to $100 \mu \mathrm{l}$ of plasma. Magnesium in the urine was measured by absorption flame spectrophotometry with a PerkinElmer instrument (10). Urinary sodium and potassium were measured by emission spectrophotometry with a Zeiss instrument. Urinary inulin was measured by an automated procedure with a Technicon Autoanalyzer (11).

The technique of long-term perfusion of the rat was developed as a modification of that described by Cotlove (12). With rats under ether anesthesia, a no. 240 polyethylene catheter ${ }^{1}$ was placed in the urinary bladder, a no. 50 polyethylene catheter ${ }^{1}$ was placed in the external jugular vein, and the parathyroid or both thyroid and parathyroid glands were removed by surgical means. In some instances parathyroidectomy was per-

\footnotetext{
${ }^{1}$ Clay-Adams Co., New York, N. Y.
} 
TABLE I

Electrolyte balance during period of control infusion

\begin{tabular}{|c|c|c|c|c|c|}
\hline & $\begin{array}{c}\text { No. of } \\
\text { experi- } \\
\text { ments }\end{array}$ & $\mathrm{Na}$ & $\mathrm{K}$ & $\mathbf{M g}$ & $\mathrm{Ca}$ \\
\hline PTX* & & umoles $/ h r$ & 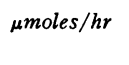 & umoles $/ h r$ & нmoles $/ \mathrm{hr}$ \\
\hline $\begin{array}{l}+D \\
-D\end{array}$ & $\begin{array}{l}6 \\
5\end{array}$ & $\begin{array}{l}+38 \pm 4 \dagger \\
+26 \pm 4\end{array}$ & $\begin{array}{l}-11 \pm 3 \\
-22 \pm 4\end{array}$ & $\begin{array}{l}+3 \pm 0.5 \\
+1 \pm 0.25\end{array}$ & $\begin{array}{l}+10 \pm 2 \\
+14 \pm 3\end{array}$ \\
\hline $\begin{array}{c}\text { High Ca } \\
-\mathrm{D}\end{array}$ & 4 & & & & $+8 \pm 1$ \\
\hline $\begin{array}{l}\text { Sham } \\
+\mathrm{D} \\
-\mathrm{D}\end{array}$ & $\begin{array}{l}4 \\
4\end{array}$ & $\begin{array}{l}+28 \pm 5 \\
-15 \pm 3\end{array}$ & $\begin{array}{l}-16 \pm 4 \\
-9 \pm 2\end{array}$ & $\begin{array}{l}-2 \pm 0.5 \\
+4 \pm 0.5\end{array}$ & $\begin{array}{l}+8 \pm 2 \\
+13 \pm 3\end{array}$ \\
\hline
\end{tabular}

* PTX = parathyroidectomized rats; high $\mathrm{Ca}=$ rats fed a high calcium vitamin D-deficient diet; sham = sham-operated control rats. $\dagger$ Mean \pm standard deviation.

formed with an electric cautery. After surgery, the animal was placed in a cage similar to that designed by Cotlove (12) with the jugular vein catheter exiting through the top and the bladder catheter and hind legs through the rectangular opening in the bottom. The jugular vein catheter was connected to a peristaltic pump that delivered 3.0 to $4.0 \mathrm{ml}$ per hour. The animals were perfused at this rate with a solution containing $4 \%$ dextrose, $5 \mathrm{mM}$ calcium chloride, $5 \mathrm{mM}$ magnesium chloride, $20 \mathrm{mM}$ sodium chloride, $2.5 \mathrm{mM}$ potassium chloride, and $20 \mathrm{mg}$ per $\mathrm{L}$ inulin. Urine was collected at half-hour or 2-hour intervals. The animals were perfused for 16 hours after surgery before measurements of urinary volume and determinations of electrolyte content were begun. Collections were then made during a control period of at least 10 hours before parathyroid hormone ( $5 \mu \mathrm{g}$ per hour) was added to the perfusate. Hormone infusion was usually continued for 20 hours, and then a period without hormone was recorded. We obtained blood samples by cardiac puncture before surgery in order to measure plasma calcium and phosphate. This was done to be certain of the degree of $\mathrm{D}$ deficiency or $\mathrm{D}$ repletion. Rats were considered D deficient only if they had stopped gaining weight after 3 weeks of vitamin $D$-free diet and if the concentration of calcium in the plasma (plasma calcium) was below $6.5 \mathrm{mg}$ per $100 \mathrm{ml}$. The mean plasma calcium value of the $D$-fed controls was $10.8 \pm 0.4 \mathrm{mg}$ per 100 $\mathrm{ml}$ before surgery. One group of animals was raised on a high calcium vitamin $\mathrm{D}$-free diet, and their mean preoperative plasma calcium was $9.6 \pm 0.3 \mathrm{mg}$ per $100 \mathrm{ml}$. These animals did not stop gaining weight but were considered vitamin $\mathrm{D}$ deficient because littermates raised on a normal calcium $\mathrm{D}$-deficient diet in adjacent individual cages exhibited classic disturbances in growth and plasma calcium levels. The number of animals studied in each group is indicated in the Figure legends; standard statistical methods were used to obtain values for standard error of the mean and significance of the differences between means (13).

The purified parathyroid hormone used was prepared by the method of Hawker, Glass, and Rasmussen (14).

\section{Results}

Initially, the reproducibility of the perfusion technique was established. Two problems of immediate concern were the stability of the base-line rates of electrolyte excretion and the balance of fluid and electrolytes.

We found that 10 to 15 hours of perfusion with the control solution was necessary before the rates of excretion of the various electrolytes became stable. Therefore, in all experiments to be reported, the animals were perfused for at least 15 hours before urine collections were begun. Collections over the ensuing 10 hours constituted the control period for each experiment.

After the postsurgical equilibration period, the rates of urine flow were from 0.05 to $0.1 \mathrm{ml}$ per hour less than the measured rates of perfusate infusion in all the animals. However, there appeared to be no significant fluid retention. The animals weighed 3 to $4 \mathrm{~g}$ less after a 50-hour experiment than before surgery. Postmortem examination revealed no evidence of abnormal fluid

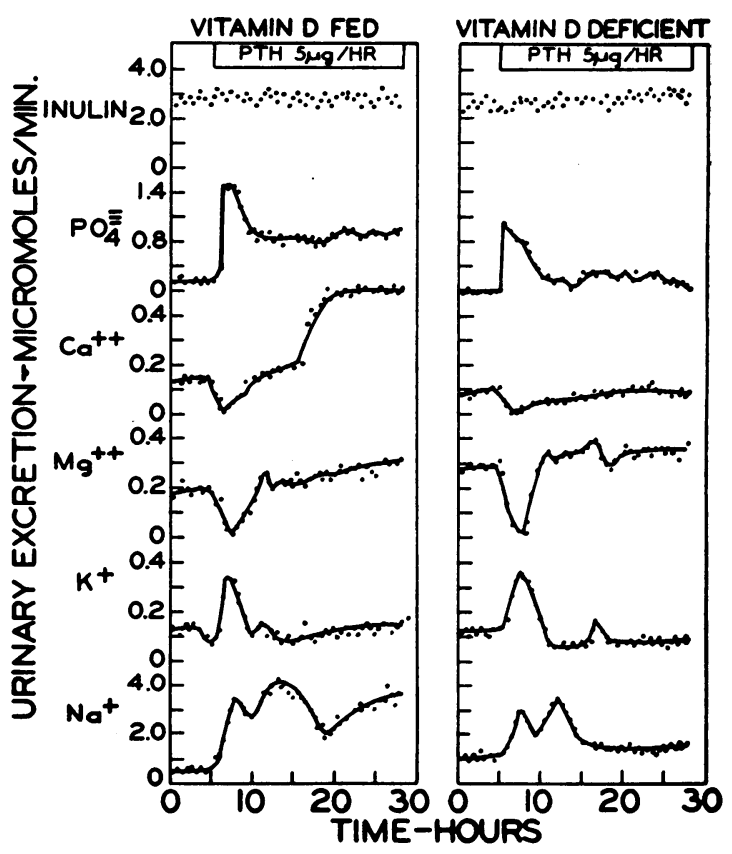

Fig. 1. Rates of excretion of inulin, phosphate, CALCIUM, MAGNESIUM, POTASSIUM, AND SODIUM BEFORE AND DURING THE INFUSION OF PARATHYROID HORMONE (PTH). Five $\mu \mathrm{g}$ per hour PTH was infused into a D-fed (left) and a D-deficient (right) parathyroidectomized rat maintained on a constant infusion of glucose and electrolytes. 
retention, and the rates of infusion were less than the maximal rates the rats could tolerate. Rates of urine flow up to 5.0 to $6.0 \mathrm{ml}$ per hour could be produced by increasing the rate of infusion. Because of these facts, it was concluded that the slight discrepancies between rates of infusion and rates of urine flow were accounted for by insensible water loss and possibly by slight evaporation from the urine samples when they were in the fraction collector. It should be noted, however, that there was usually sodium retention and always potassium loss during the control period (Table I), possibly as a result of adrenal hyperactivity secondary to the stress of surgery and experimentation. In all instances in which sodium retention occurred, it was followed by sodium diuresis during hormone infusion (Figures 1 and 2). Magnesium excretion balanced intake, but there was always calcium retention that was more marked in the D-deficient than in the D-fed animals (Table I).

Our initial studies were carried out in parathyroidectomized animals. Two typical experiments are shown in Figure 1. In the rat fed vitamin $D$, the infusion of parathyroid hormone at a rate of $5 \mu \mathrm{g}$ per hour led to a prompt increase in the rate of excretion of phosphate, potassium, and sodium, and an initial fall in magnesium and calcium excretion (Figure 1). The changes in rates of magnesium and potassium excretion were not sustained but returned to baseline or slightly greater values after 4 to 6 hours of perfusion. In contrast, the initial phosphaturia was followed by a sustained phosphate excretion throughout the course of the perfusion. Calcium excretion, after decreasing initially, returned to the control rate and then rose, after 15 to 22 hours of constant hormone perfusion, to a rate considerably higher than that observed initially. Changes in the rate of sodium excretion were more variable but in general paralleled those of phosphate.

In contrast, the infusion of hormone at the same rate into a $\mathrm{D}$-deficient parathyroidectomized rat led to the initial changes in electrolyte excretion that were qualitatively similar to those seen in the D-fed animal, i.e., an increased rate of sodium, potassium, and phosphate excretion, and a fall in excretion of calcium and magnesium. However, a different pattern of response emerged during the later hours of perfusion (Figure 1). The rate of

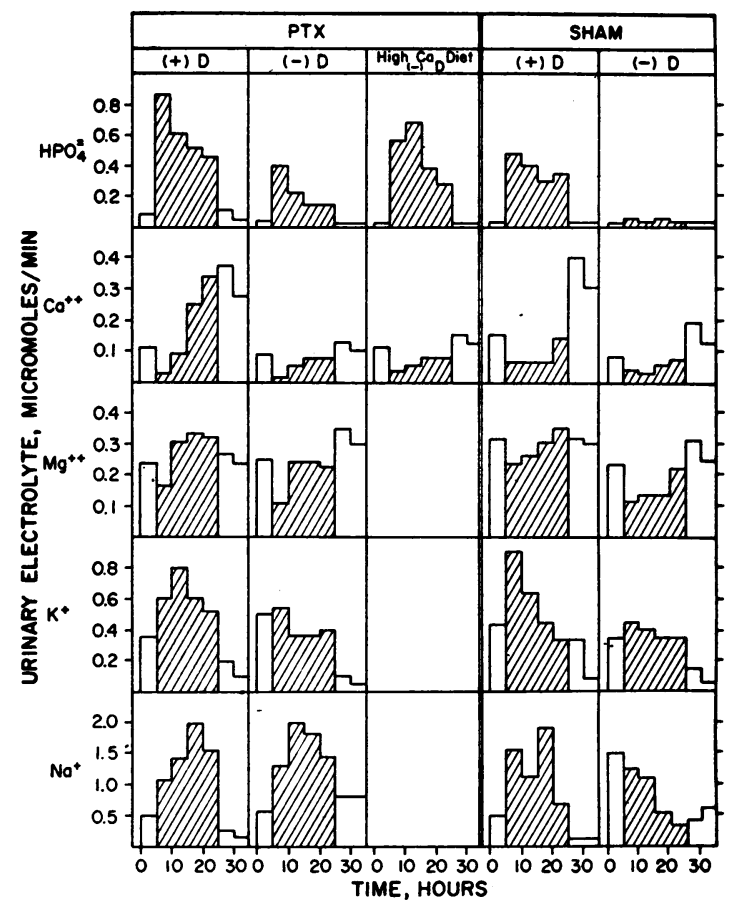

Fig. 2. Patterns of URinary electrolyte excretion BEFORE, DURING, AND AFTER THE INFUSION OF PARATHYROID HORMONE, $5 \mu \mathrm{G}$ PER HOUR, IN PARATHYROIDECTOMIZED (PTX) AND SHAM-OPERATED D-DEFICIENT AND D-FED RATS. All animals were maintained on a normal calcium and phosphate diet, except the third group of D-deficient animals, which were maintained on a high calcium normal phosphate diet. The shaded areas represent the values during hormone infusion. Number of animals in each group: $+\mathrm{D}, 6 ;-\mathrm{D}, 5 ;-\mathrm{D}$ high calcium diet, $4 ;+\mathrm{D}$ sham, 4 ; $-\mathrm{D}$ sham, 4.

phosphate excretion fell, after the initial increase, to rates only slightly greater than the control rates; the initial decrease in rate of calcium excretion was followed by a gradual return to a rate nearly equal to, but never in excess of, the control. Also, sodium diuresis was not sustained as in the D-fed animal.

The rates of inulin excretion were also measured in these animals. There was no significant change in the excretion of constantly infused inulin during hormone infusion in either animal (Figure 1). Rates of inulin excretion were measured in six additional animals, and in all instances the infusion of parathyroid hormone at a rate of $5 \mu \mathrm{g}$ per hour had no effect upon this rate.

The same protocol was followed in six other $\mathrm{D}$-fed and five other D-deficient animals. The results are recorded as the means of the values 
TABLE II

Comparison of responses to parathyroid hormone infusion in parathyroidectomized vitamin $D$-fed and D-deficient rats

\begin{tabular}{|c|c|c|c|c|c|c|}
\hline \multirow[b]{2}{*}{ Animal* } & & \multicolumn{5}{|c|}{ Urinary electrolyte excretion in 5 hours } \\
\hline & & HPO4- & $\mathrm{Ca}^{++}$ & $\mathrm{Mg}$ & $\mathrm{K}$ & $\mathrm{Na}$ \\
\hline & & $\mu$ moles & umoles & umoles & «moles & umoles \\
\hline $\begin{array}{l}+\mathrm{D} \\
-\mathrm{D} \\
-\mathrm{D}(\mathrm{Ca})\end{array}$ & $\mathrm{C} \dagger$ & $\begin{aligned} 24.0 \pm & \pm .2 \\
7.5 \pm & 3.0 \ddagger \\
6.1 \pm & \pm .6 \ddagger\end{aligned}$ & $\begin{array}{l}36.0 \pm 4.4 \\
27.0 \pm 3.4 \\
34.0 \pm 4.7\end{array}$ & $\begin{array}{l}69.0 \pm 5.2 \\
75.0 \pm 5.8\end{array}$ & $\begin{array}{l}108 \pm 10 \\
150 \pm 11 \ddagger\end{array}$ & $\begin{array}{l}150 \pm 13 \\
180 \pm 17\end{array}$ \\
\hline $\begin{array}{l}+D \\
-D \\
-D(C a)\end{array}$ & 5 & $\begin{array}{l}258.0 \pm 20 \\
120.0 \pm 9 \ddagger \\
204.0 \pm 12 \S\end{array}$ & $\begin{array}{l}7.5 \pm 2.3 \\
3.6 \pm 0.9 \ddagger \\
8.0 \pm 2.5\end{array}$ & $\begin{array}{l}48.0 \pm 5.8 \\
33.0 \pm 4.9 \S\end{array}$ & $\begin{array}{l}180 \pm 12 \\
165 \pm 11\end{array}$ & $\begin{array}{l}330 \pm 12 \\
390 \pm 14 \ddagger\end{array}$ \\
\hline $\begin{array}{l}+D \\
-D \\
-D(C a)\end{array}$ & 10 & $\begin{array}{r}188.0 \pm 15 \\
65.0 \pm 8 \ddagger \\
225.0 \pm 17\end{array}$ & $\begin{array}{l}28.0 \pm 4.3 \\
17.0 \pm 5.2 \ddagger \\
12.0 \pm 3.2 \ddagger\end{array}$ & $\begin{array}{l}81.6 \pm 6.3 \\
73.0 \pm 6.2\end{array}$ & $\begin{array}{l}236 \pm 15 \\
124 \pm 12 \ddagger\end{array}$ & $\begin{array}{l}414 \pm 16 \\
580 \pm 23 \ddagger\end{array}$ \\
\hline $\begin{array}{l}+\mathrm{D} \\
-\mathrm{D} \\
-\mathrm{D}(\mathrm{Ca})\end{array}$ & 15 & $\begin{array}{c}151.0 \pm 17 \\
44.0 \pm 9 \ddagger \\
143.0 \pm 16\end{array}$ & $\begin{array}{l}90.3 \pm 8.8 \\
22.0 \pm 4.0 \ddagger \\
23.0 \pm 5.1 \ddagger\end{array}$ & $\begin{array}{l}89.4 \pm 7.0 \\
73.0 \pm 5.8\end{array}$ & $\begin{array}{l}179 \pm 8 \\
124 \pm 12 \ddagger\end{array}$ & $\begin{array}{l}571 \pm 29 \\
521 \pm 20 \S\end{array}$ \\
\hline $\begin{array}{l}+\mathrm{D} \\
-\mathrm{D} \\
-\mathrm{D}(\mathrm{Ca})\end{array}$ & 20 & $\begin{array}{r}138.0 \pm 16 \\
44.0 \pm 11 \ddagger \\
99.0 \pm 17 \S\end{array}$ & $\begin{aligned} & 107.7 \pm 9.0 \\
& 22.0 \pm \pm .3 \ddagger \\
& 23.0 \pm 6.6 \ddagger\end{aligned}$ & $\begin{array}{l}83.2 \pm 5.8 \\
69.0 \pm 7.1 \S\end{array}$ & $\begin{array}{l}155 \pm 13 \\
132 \pm 14 \S\end{array}$ & $\begin{array}{l}487 \pm 26 \\
430 \pm 12 \S\end{array}$ \\
\hline $\begin{array}{l}+D \\
-D \\
-D(C a)\end{array}$ & $\mathrm{PH}$ & $\begin{array}{cc}30.0 \pm & 4.2 \\
5.0 \pm & 2.2 \ddagger \\
4.8 \pm & 2.4 \ddagger\end{array}$ & $\begin{array}{r}127.6 \pm 11.0 \\
42.6 \pm 7.1 \ddagger \\
51.7 \pm 9.3 \ddagger\end{array}$ & $\begin{array}{l}78.2 \pm 6.0 \\
91.3 \pm 8.3\end{array}$ & $\begin{array}{l}55 \pm 7 \\
40 \pm 8\end{array}$ & $\begin{array}{c}77 \pm 11 \\
208 \pm 15 \ddagger\end{array}$ \\
\hline
\end{tabular}

* $+D=6$ vitamin $D$-fed controls; $-D=5$ vitamin D-deficient rats on normal calcium intake; $-D(C a)=4$ vitamin D-deficient rats on high calcium intake.

$+\mathrm{C}=$ excretion during 5-hour control period; 5, 10,15, $20=$ excretion during first 5, 10, 15, 20 hours of hormone infusion; and $\mathrm{PH}=$ excretion during 5 hours after hormone infusion.

$\mp \mathrm{p}<0.001$ when values (mean \pm standard error) between $+\mathrm{D}$ and $-\mathrm{D}$ animals are compared.

$\S \mathrm{p}<0.025$ when values (mean \pm standard error) between $+\mathrm{D}$ and $-\mathrm{D}$ animals are compared.

for 5-hour periods before, during, and after hormone perfusion in Figure 2 (columns 1 and 2). Also shown are the responses of four shamoperated animals (Figure 2, columns 4 and 5), and the changes in urinary calcium and phosphate excretion on a high calcium, normal phosphate diet (Figure 2, column 3). Table II summarizes the electrolyte data and gives the results of the statistical evaluation of the differences between the mean values for the various 5 -hour periods between D-fed and D-deficient animals. Table III shows the mean plasma calcium and phosphate values of animals in each group before surgery, during the period of control perfusion, and after 12 hours of hormone infusion. All three measurements could not be made in all animals in each group. Because of the small number of values in some groups, the mean and range in each group are recorded rather than the standard error.

The plasma values and the changes in electrolyte excretion were highly reproducible from one animal to the next within a given group but varied considerably from group to group. Early in the course of this project, a single bloodletting frequently led to a significant decrease in the urinary output during the next 0.5 -hour period, but the urinary output returned to the previous level thereafter. After further experience, it was possible to obtain three blood samples from a single animal within a 24-hour period without greatly altering the rate of urine flow. The number of measurements within each group was too few to obtain precise statements of significance, but as seen in Table III, the results were clear. There was no significant rise in plasma calcium in the D-deficient animals of any group after hormone infusion, although in each instance there was a tendency for the value to rise slightly. On the other hand, there was a rise in plasma calcium in the D-fed animals (Table III). The plasma phosphate decreased in all animals except in the intact D-deficient ones (Table III).

The slight rise in plasma calcium seen in all D-deficient animals was associated with definite 
TABLE III

Plasma calcium and phosphate values in rats before parathyroidectomy or thyroparathyroidectomy, during the control infusion, and after 12 hours of hormone infusion

\begin{tabular}{|c|c|c|c|c|c|c|c|c|}
\hline \multirow[b]{2}{*}{ Status } & \multirow[b]{2}{*}{ Vitamin D } & \multirow[b]{2}{*}{ No. rats } & \multicolumn{3}{|c|}{ Plasma calcium } & \multicolumn{3}{|c|}{ Plasma PO, } \\
\hline & & & Pre-op.* & Control inf. $\dagger$ & PTH & Pre-op.* & Control inf. $\dagger$ & PTH \\
\hline $\begin{array}{l}\text { PTX } \\
\text { PTX }\end{array}$ & \pm & $\begin{array}{l}4 \\
4\end{array}$ & $\begin{array}{r}11.1 \pm 0.4 \\
6.0 \pm 0.2\end{array}$ & $\begin{array}{l}m g / 100 m l \\
8.4 \pm 0.4 \\
7.0 \pm 0.4\end{array}$ & $\begin{array}{r}13.1 \pm 0.6 \\
8.1 \pm 0.3\end{array}$ & $\begin{array}{l}11.3 \pm 0.3 \\
11.4 \pm 0.3\end{array}$ & $\begin{array}{c}m g / 100 m l \\
10.2 \pm 0.5 \\
10.8 \pm 0.3\end{array}$ & $\begin{array}{l}7.4 \pm 0.4 \\
8.4 \pm 0.3\end{array}$ \\
\hline PTX $\S$ & $\mathrm{High} \mathrm{Ca}$ & 4 & $9.6 \pm 0.3$ & $8.3 \pm 0.3$ & $8.9 \pm 0.4$ & $9.3 \pm 0.4$ & $8.9 \pm 0.3$ & $6.2 \pm 0.5$ \\
\hline $\begin{array}{l}\text { Intact } \\
\text { Intact }\end{array}$ & \pm & $\begin{array}{l}3 \\
2\end{array}$ & $\begin{array}{r}11.4 \pm 0.3 \\
6.1 \pm 0.3\end{array}$ & $\begin{array}{r}10.2 \pm 0.3 \\
7.1 \pm 0.2\end{array}$ & $\begin{array}{r}12.2 \pm 0.3 \\
7.2 \pm 0.2\end{array}$ & $\begin{array}{l}11.3 \pm 0.4 \\
11.8 \pm 0.3\end{array}$ & $\begin{array}{l}10.7 \pm 0.4 \\
10.8 \pm 0.4\end{array}$ & $\begin{array}{r}8.6 \pm 0.1 \\
10.4 \pm 0.3\end{array}$ \\
\hline $\begin{array}{l}\text { TXPTX } \\
\text { TXPTX }\end{array}$ & \pm & $\begin{array}{l}4 \\
4\end{array}$ & $\begin{array}{r}10.8 \pm 0.3 \\
6.1 \pm 0.2\end{array}$ & $\begin{array}{l}8.8 \pm 0.3 \\
9.2 \pm 0.4\end{array}$ & $\begin{array}{r}18.2 \pm 1.4 \\
9.8 \pm 0.4\end{array}$ & $\begin{array}{l}11.2 \pm 0.4 \\
10.8 \pm 0.4\end{array}$ & $\begin{array}{l}11.0 \pm 0.2 \\
10.6 \pm 0.3\end{array}$ & $\begin{array}{l}7.2 \pm 0.4 \\
7.3 \pm 0.5\end{array}$ \\
\hline
\end{tabular}

* Values before surgery.

† Values after surgery and at least 10 to 12 hours of perfusion with control solution.

¥ Values after 12 hours of parathyroid hormone (PTH) infusion.

$\$$ Maintained on a high calcium vitamin D-deficient diet.

II Thyroparathyroidectomized.

T These D-deficient animals were perfused with a solution containing $25 \mathrm{M} \mathrm{CaCl}_{2}$ rather than the usual $5 \mathrm{mM}$ concentration:

renal retention of calcium during hormone infusion and a slight calcium diuresis after the hormone infusion stopped (Figure 2, columns 2 and $3)$. This pattern was also seen in the intact D-fed animals, but in the D-fed parathyroidectomized animals the initial retention of calcium was followed by a marked diuresis.

It is noteworthy that the magnitude of the initial (first 5 hours) phosphaturia seen in the D-deficient animals (Figure 2, column 2) was approximately $50 \%(\mathrm{p}<0.001)$ and the potassium diuresis $20 \%$ of that seen in the D-fed animals (Figure 2, column 1). Conversely, the initial magnesium retention was twice as great in the $D$-deficient animals as in the D-fed $(p<0.025)$ (Figure 2, columns 1 and 2). Also, the initial magnesium retention in the $\mathrm{D}$-fed animals was followed by a diuresis of magnesium during the later hours of hormone infusion, whereas this did not occur in the D-deficient animals although the latter had a magnesium diuresis after the cessation of hormone infusion.

If D-deficient animals were maintained on a high calcium diet during the entire period before study, their initial phosphaturia during the first 10 hours of hormone perfusion was considerably greater $(p<0.01)$ than that seen in D-deficient animals raised on a normal calcium diet (Figure 2 , columns 2 and 3 ), and was approximately $80 \%$ of that seen in the D-fed animals (Figure 2, columns 1 and 3). The results in Figure 2, column 3 represent the mean values of four animals.

Animals subjected to a sham operation rather than parathyroidectomy responded differently than did the parathyroidectomized animals. Those fed vitamin D (Figure 2, column 4) had qualitatively similar initial changes (compared to D-fed parathyroidectomized animals) in rates of electrolyte excretion. However, the magnitude of the phosphaturia was significantly less $(p<0.01)$ than that seen in parathyroidectomized animals, and the marked secondary rise in rate of calcium excretion, normally seen in the parathyroidectomized rats, was not seen in the sham-operated one. However, after the cessation of hormone infusion in these latter animals, a striking calcium diuresis was always observed. In contrast, D-deficient sham-operated animals had no significant change in potassium or phosphate excretion during hormone infusion although the rates of excretion of sodium, calcium, and magnesium all fell significantly $(p<0.01)$ and rose again only upon cessation of hormone infusion.

The lack of both a rise in plasma calcium (Table III) and a secondary calcium diuresis (Figures 1 and 2, columns 2 and 3 ) in the D-deficient parathyroidectomized animals was interpreted to mean that the parathyroid hormone was 
TABLE IV

Phosphate balances in D-deficient rats given parathyroid hormone*

\begin{tabular}{lcccc}
\hline \hline \multicolumn{1}{c}{ Rats } & No. & Diet & $\begin{array}{c}\text { Total } \\
\text { decrease } \\
\text { ECF HPO }\end{array}$ & $\begin{array}{c}\text { Excess } \\
\text { urinary } \\
\text { HPO }\end{array}$ \\
\hline & & & \multicolumn{2}{c}{${ }^{\mu m o l e s}$} \\
PTX & 4 & Normal Ca & 24 & $150 \ddagger$ \\
PTX & 3 & High Ca & 27 & $330 \ddagger$ \\
TXPTX & 4 & Normal Ca & 27 & $128 \ddagger$ \\
\hline
\end{tabular}

* Calculated from the data in Figure 2, columns 2 and 3; Figure 3, column 2; and Tables II and III.

$\mathrm{ECF}=$ extracellular fluid.

‡ Significantly greater $(p<0.001)$ than the total decrease in ECF phosphate.

unable to mobilize calcium from bone. If this was the case, it could be argued that it would also be unable to mobilize phosphate from bone. The question then arose as to the source of the urinary phosphate seen in the D-deficient animals (Figure 2 , columns 2 and 3 ). From the data in Figure 2 (columns 2 and 3 ) and Table III, it was possible to calculate the excess phosphate appearing in the urine of the $\mathrm{D}$-deficient animals during the first 10 hours of hormone infusion. This was done by subtracting the rates during the control period from those seen in the first two 5-hour periods of hormone infusion. The difference was taken as a measure of phosphate loss and recorded in Table IV as excess urinary $\mathrm{HPO}_{4}{ }^{\circ}$. The total loss of phosphate from plasma and extracellular fluids was calculated from the differences in the plasma phosphate concentrations seen during the control infusion and after 12 hours of hormone infusion (Table I), assuming the plasma and the extracellular fluid volume to be $20 \%$ of the body weight. These values are recorded in Table IV as total decrease in extracellular fluid (ECF) $\mathrm{HPO}_{4}=$. In both instances, the phosphate appearing in the urine was considerably in excess of that which disappeared from the extracellular fluids $(p<0.001)$. This was true even if the total ECF volume was as great as $30 \%$ of the body weight.

Because of the recent evidence that thyrocalcitonin suppresses the action of parathyroid hormone upon bone resorption (15), it was considered important to determine whether thyrocalcitonin was involved in the altered responses of the D-deficient animals to parathyroid hormone infusion. For this purpose, four D-deficient and four D-fed animals were thyroparathyroidectomized and per- fused. The changes in plasma calcium and phosphate and in the rates of urinary excretion of calcium and phosphate are shown in Figure 3 and Table III. In all the D-fed animals, the initial phosphaturia was equal to that seen in the parathyroidectomized animals (compare Figure 3, column 1, with Figure 2, column 1). However, there was no initial calcium retention as seen in the parathyroidectomized animals. Calcium excretion rose slightly during the first 6 hours and then rapidly over the next 6 . This was associated with a striking rise in plasma calcium [from 8.8 to 18.2 as compared to 8.4 to 13.1 in the para-

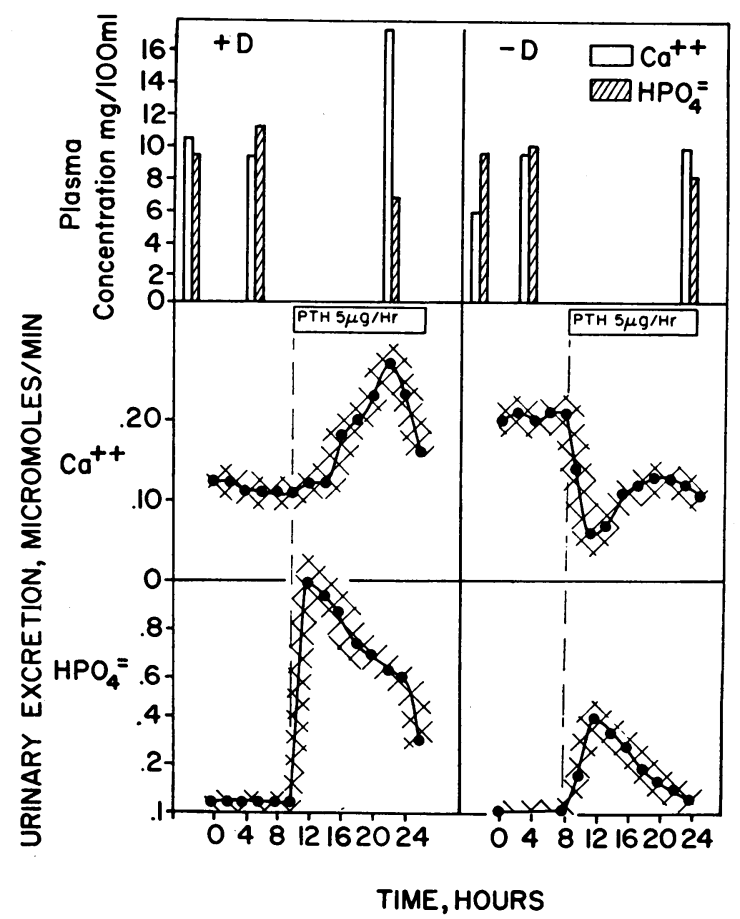

Fig. 3. Concentrations of Calcium and phosphate IN PLASMA AND RATES OF EXCRETION OF CALCIUM AND PHOSPHATE IN THE URINE BEFORE AND DURING THE INFUSION OF PTH INTO THYROPARATHYROIDECTOMIZED D-FED (LEFT) AND D-DEFICIENT (RIGHT) RATS. There were four animals in each group. The shaded areas along the lower curves represent the range of values, and the heavy line represents the mean. The first pair of plasma values in each case represents the values obtained before the animals were operated on. The latter two pairs represent values taken during the control period and during the period of hormone infusion, respectively. Note that the D-deficient animals were infused with a more concentrated solution of calcium chloride so that the concentration of calcium in their plasma during the period of control infusion was nearly identical to that seen in the D-fed controls. 
thyroidectomized animal (Table III)]. The rates of excretion of both calcium and phosphate fell during the last 4 hours of perfusion, but after 16 to 20 hours of hormone infusion these animals developed oliguria and died. The decline in calcium and phosphate excretion coincided with the onset of oliguria. The apparent cause of death was gross nephrocalcinosis. Because of this, perfusion could not be continued as long in these animals.

In contrast to the D-fed animals, the responses of thyroparathyroidectomized D-deficient animals were not very different from those seen in parathyroidectomized D-deficient animals (compare Figure 3, column 2, with Figure 2, column 2). In an attempt to make the experimental situation between D-fed and D-deficient animals as comparable as possible, we infused the thyroparathyroidectomized D-deficient animals with a solution containing 25 rather than $5 \mathrm{mM} \mathrm{CaCl}_{2}$. This was sufficient to raise their plasma calcium concentrations to values slightly greater than those of the D-fed animals (Table III and Figure 3 ). This led to a much higher rate of calcium excretion and to the complete disappearance of phosphate from the urine during the control period (Figure 3). In spite of the high rate of urinary calcium excretion, the animals were in significant positive calcium balance, approximately $60 \mu$ moles per hour. Parathyroid hormone infusion led to a prompt and striking fall in urinary calcium, which remained below control values throughout the period of hormone infusion. Phosphaturia was also observed and was approximately $40 \%$ of that seen initially in the D-fed controls (Figure 3). The total excess phosphate in the urine was significantly greater $(p<0.001)$ than that which disappeared from the ECF (Table IV). The plasma calcium rose only slightly, 9.2 to $9.8 \mathrm{mg}$ per $100 \mathrm{ml}$, as compared to the striking rise, 8.8 to 18.2 , seen in the D-fed animals. In spite of the high initial rates of calcium infusion and excretion, these animals did not develop nephrocalcinosis.

\section{Discussion}

The present results extend our previous observations (6) and those of Harrison and Harrison (7). In D-deficient rats with intact parathyroid glands, the injection $(6,7)$ or infusion of parathyroid hormone (Figure 2, column 5, and Table
II) led to no change in plasma calcium or phosphate and no change in the urinary excretion of phosphate. However (Figure 2, column 5), a significant $(p<0.025)$ decrease in magnesium and sodium and a slight decrease in calcium excretion were observed. Removal of the parathyroid or both thyroid and parathyroid glands of these animals altered this pattern of response. Plasma phosphate fell after hormone infusion (Table III), and phosphaturia as well as magnesium and calcium retention occurred (Figure 2, columns 2 and 3 ; and Figure 3, column 2). Plasma calcium rose slightly, but in no instance was this significant $(p<0.2)$. This slight rise in plasma calcium was thought to be a consequence of renal retention of calcium. Furthermore, the responses of the thyroparathyroidectomized D-deficient animals (Figure 3 , column 2) indicate that the lack of calcium mobilization during hormone infusion was not due to the presence of excess thyrocalcitonin. This is in sharp contrast to the results of hormone perfusion in $\mathrm{D}$-fed animals. The presence of the thyroid gland altered the pattern of response of this group (compare Figure 2, column 1, and Figure 3, column 1). In the absence of endogenous thyrocalcitonin, parathyroid hormone led to a more rapid mobilization of calcium from bone. During the same period, the infusion of hormone into D-deficient animals maintained on a much higher rate of calcium infusion led to no significant hypercalcemia, but to a striking decrease in the rate of urinary calcium excretion (Figure 3 ).

The major differences in the responses of the parathyroidectomized D-deficient and D-fed rats to the long-term infusion of parathyroid hormone are the less marked initial phosphate and potassium diuresis, the lack of delayed hypercalciuria, and the poorly sustained phosphaturia in the D-deficient group (Figures 1 and 2). The latter two findings probably reflect the failure of the hormone to induce the mobilization of calcium and phosphate from bone in the absence of vitamin D. If this conclusion is accepted, then the data shown in Table IV indicate that parathyroid hormone mobilizes phosphate from a source other than the bone and extracellular fluids, presumably the intracellular fluids. This in turn implies that parathyroid hormone alters intracellular electrolyte concentrations as well as those in extracellular fluids, a point that has been discussed previously 
in relation to the effects of this hormone on isolated mitochondria (1).

The less marked initial phosphaturia seen in the D-deficient animals (Figure 2, column 2 vs. column 1 ; and Figure 3 ) is difficult to explain. There are several possibilities. It is conceivable that the rats employed in these studies were not adequately depleted of vitamin $\mathrm{D}$ and that this vitamin is necessary for the action of parathyroid hormone on the renal tubule as well as on bone. However, if one considers the total response of the tubule to hormone infusion, then it is apparent that the quantitative changes in excretion of sodium and calcium were similar in D-fed and D-deficient parathyroidectomized animals; that the changes in magnesium excretion were greater $(\mathrm{p}<0.025)$ in the D-deficient animals (Figure 2, columns 1 and 2); and that even in D-deficient sham-operated animals (Figure 2, column 5) a change in magnesium and calcium excretion was observed. Thus, by some criteria, the kidney of the D-deficient animal responds to parathyroid hormone as well as or better than that of the D-fed animal, but by others it responds less well.

One possibility that may account for the differences in phosphate excretion in the different groups of animals is that they had varying degrees of secondary hyperparathyroidism before these experiments were undertaken; it is possible that this altered the concentrations of intracellular electrolytes and consequently renal responses. There is increasing evidence $(6,16,17)$ that significant hyperparathyroidism exists in vitamin D-deficient rats maintained on a normal calcium intake. This appears to be a consequence of the hypocalcemia that results from the vitamin deficiency $(6,17)$ and can be prevented in large part by putting these animals on high calcium intakes $(6,17)$. In the present context, perhaps the most important consequence of chronic secondary hyperparathyroidism is possible depletion of intracellular phosphate stores. It is important to point out that, although our animals were studied after their parathyroid glands had been removed, they received no phosphate after this surgery and hence would not have repleted tissue stores of this substance. The most obvious difference between D-deficient animals on a normal and on a high calcium intake (Figure 2, columns 2 and 3 ; and Table III) is that the former have low levels of plasma calcium and the latter have high levels. Thus, the latter would not have secondary hyperparathyroidism [see also (17)], and the response of these animals measured in terms of phosphate excretion (Figure 2, column 3; and Table II) and plasma phosphate (Table III) was similar to that seen in D-fed controls (Figure 2, column 1). On the other hand, the D-deficient animals with hypocalcemia undoubtedly had secondary hyperparathyroidism with resultant changes in phosphate metabolism (6), and their response measured as phosphate excretion (Figure 2, column 2) was significantly less than that of the $\mathrm{D}$-fed controls. This difference would account for the fact that parathyroid hormone mobilized less total phosphate in the D-deficient animals on a normal calcium intake than it did in the D-deficient animals on a high calcium intake (Table IV). The acceptance of this proposal must await the demonstration that parathyroid hormone alters intracellular phosphate concentrations. These studies are in progress.

The results with the group of D-deficient animals fed a high calcium diet (Figure 2, column 3; and Table III) were of importance for another reason. These animals had the same plasma calcium values as the D-fed animals (Table III) during the period of control infusion (before hormone infusion) and the same degree of calcium retention during this period (Table I). Nevertheless, the infusion of hormone into these D-deficient animals did not lead to significant rise in plasma calcium (Table III) or delayed hypercalciuria as seen in the D-fed animals (Figure 2, columns 3 and 1). Also the fall in plasma phosphate concentration was as great in this group of animals as that seen in the D-fed ones (2.8 vs. 2.7, Table III). Thus, in terms of initial changes in phosphate metabolism, the two groups were nearly identical; in spite of this, parathyroid hormone did not mobilize calcium from bone. These data constitute the strongest argument in support of our previous thesis (6) that parathyroid hormone is unable to mobilize calcium from bone in D-deficient rats but is still able to exert its usual effects on renal function.

This thesis is also supported by the recent studies of the effect of inhibitors of RNA and protein synthesis upon the response of rats to parathyroid hormone and vitamin $\mathrm{D}(8,18,19)$. The infu- 
sion of parathyroid hormone into an actinomycintreated rat leads to the same pattern of urinary electrolyte changes (8) as seen in the D-deficient rat (Figures 2 and 3 ), that is, the early renal response is normal, but the secondary changes due to mobilization of calcium and phosphate from bone are absent. Similarly, Zull, Czarnowska-Misztal, and DeLuca (18) and Norman (19) have shown that prior treatment with actinomycin D blocks the normal response of vitamin D-deficient rats to the administration of vitamin $\mathrm{D}$.

Thus, evidence gathered by several different means leads to the conclusion that vitamin $D$ is necessary for the expression of some, but not all, effects of parathyroid hormone. The problem that develops is that of accounting for the divergent views of others $(4,5,7,20)$. There is no basic disagreement between our data and those of Harrison and Harrison (7). The important point is that, in a D-deficient rat, exogenous parathyroid hormone has little detectable influence on phosphate metabolism because of high levels of endogenous hormone, which are already exerting a nearly maximal effect. Only by removing the parathyroid glands is it possible to demonstrate a need for, or a response to, exogenous hormone (Figure 2). Other studies in rodents $(5,20)$, which have led to results different from ours and those of Harrison and Harrison, can be questioned on their lack of sufficient evidence that the animals involved were completely $\mathrm{D}$ deficient. The most serious challenge to our thesis comes from the work of Ney and associates (4). These authors concluded, on the basis of the response of D-deficient puppies to parathyroidectomy and to parathyroid extract, that parathyroid hormone exerts its usual effects on bone even in $\mathrm{D}$ deficiency. One possible explanation is that the nature of the hormone-vitamin relationship described in the present report is unique to the rat. A more likely explanation is that the dogs studied by Ney and co-workers did not have as severe a degree of $\mathrm{D}$ deficiency as that developd by the rats. One of the dogs with the most marked hypocalcemia had no change in plasma calcium after parathyroidectomy, and several others had minimal changes both after operation and after the subsequent injection of parathyroid extract. In fact, there was direct correlation between the initial level of plasma calcium and the fall observed after parathy- roidectomy (omitting animal T782, which was most unusual), and all animals were initially hypocalcemic. These results could be accounted for if the animals studied had varying degrees of $\mathrm{D}$ deficiency, and they are similar to our previous observations in the rat (6).

Unfortunately, there is as yet no simple method by which the degree of $\mathrm{D}$ deficiency can be assessed in experimental animals; hence, it is not an easy matter to resolve all controversy. Nevertheless, in the species in which the degree of deficiency can be best controlled, the rat, it seems clear that vitamin $\mathrm{D}$ is necessary for physiologic concentrations of parathyroid hormone to mobilize calcium and phosphate from bone. On the other hand, there appears to be no vitamin $\mathrm{D}$ requirement for the expression of parathyroid hormone action at the level of the renal tubule.

\section{Summary}

The response of the D-deficient parathyroidectomized rat to the infusion of parathyroid hormone is different from that of a D-fed control. Both exhibited qualitatively similar initial changes in plasma phosphate and in the urinary excretion of calcium, phosphate, magnesium, sodium, and potassium, but in the D-deficient animals sustained phosphaturia and secondary hypercalciuria and hypercalcemia did not develop as they did in the D-fed animal.

Initial phosphate excretion was less and initial magnesium retention greater in D-deficient animals raised on a normal calcium intake. However, D-deficient animals raised on a high calcium intake had nearly the same initial values of plasma calcium and changes in plasma and urinary phosphate after hormone infusion as D-fed animals raised on a normal calcium intake. In spite of this, the D-deficient animals had no rise in either plasma or urinary calcium.

Removal of the thyroid gland did not greatly alter the response of the D-deficient rat to parathyroid hormone, but a more immediate and marked calcium diuresis and hypercalcemia were observed in the D-fed animal.

We concluded that vitamin $\mathrm{D}$ is necessary for physiologic concentrations of parathyroid hormone to mobilize calcium and phosphate from bone but not for the hormone to act on the renal tubule. 


\section{Acknowledgments}

We are indebted to Dr. Maurice Pechet for his advice in regard to the perfusion technique. Mr. Charles Hawker, Miss Berit Johannson, and Miss Elizabeth Middleton all rendered valuable assistance.

\section{References}

1. Rasmussen, H., and H. F. DeLuca. Calcium homeostasis. Ergebn. Physiol. 1963, 53, 108.

2. Shelling, D. H. The Parathyroids in Health and Disease. St. Louis, C. V. Mosby, 1935.

3. Harrison, H. C., H. E. Harrison, and E. A. Park. Vitamin $\mathrm{D}$ and citrate metabolism: effect of vitamin $\mathrm{D}$ in rats fed diets adequate in both calcium and phosphorus. Amer. J. Physiol. 1958, 192, 432.

4. Ney, R. L., W. Y. W. Au, G. Kelly, I. Radde, and F. C. Bartter. Action of parathyroid hormone in the vitamin D-deficient dog. J. clin. Invest. 1965, 44, 2003.

5. Nichols, G., Jr., S. Schartum, and G. M. Vaes. Some effects of vitamin $D$ and parathyroid hormone on the calcium and phosphorus metabolism of bone in vitro. Acta physiol. scand. 1963, 57, 51.

6. Rasmussen, H., H. DeLuca, C. Arnaud, C. Hawker, and $M$. von Stedingk. The relationship between vitamin $\mathrm{D}$ and parathyroid hormone. J. clin. Invest. 1963, 42, 1940.

7. Harrison, H. E., and H. C. Harrison. The interaction of vitamin $\mathrm{D}$ and parathyroid hormone on calcium, phosphorus and magnesium homeostasis in the rat. Metabolism 1964, 13, 952.

8. Rasmussen, H., C. Arnaud, and C. Hawker. Actinomycin $D$ and the response to parathyroid hormone. Science 1964, 144, 1019.

9. Steenbock, H., and D. C. Herting. Vitamin D and growth. J. Nutr. 1955, 57, 449.
10. Willis, J. B. Determination of calcium and magnesium in urine by atomic absorption spectroscopy. Analyt. Chem. 1961, 33, 556.

11. Roe, J. H., J. H. Epstein, and N. P. Goldstein. A photometric method for the determination of inulin in plasma and urine. J. biol. Chem. 1949, 178, 839.

12. Cotlove, E. Simple tail vein infusion method for renal clearance measurements in the rat. J. appl. Physiol. 1961, 16, 764.

13. Snedecor, G. W. Statistical Methods. Ames, Iowa, Iowa State College Press, 1956.

14. Hawker, C. D., J. D. Glass, and H. Rasmussen. Further studies on the isolation and characterization of parathyroid polypeptides. Biochemistry 1966, 5, 344.

15. Friedman, J., and L. G. Raisz. Thyrocalcitonin inhibition of bone resorption in tissue culture. Science 1965, 150, 1465.

16. Crawford, J. D., D. Gribetz, W. C. Diner, P. Hurst, and B. Castleman. The influence of vitamin D on parathyroid activity and the metabolism of calcium and citrate during calcium deprivation. Endocrinology 1957, 61, 59.

17. Au, W. Y. W., and L. G. Raisz. Effect of vitamin D and dietary calcium on parathyroid activity. Amer. J. Physiol. 1965, 209, 637.

18. Zull, J. E., M. Czarnowska-Misztal, and H. F. DeLuca. On the relationship between vitamin $\mathrm{D}$ action and actinomycin-sensitive processes. Proc. nat. Acad. Sci. (Wash.) 1966, 55, 177.

19. Norman, A. W. Actinomcyin D and the response to vitamin D. Science 1965, 149, 184.

20. Toverud, S. U. The effect of parathyroid hormone and vitamin $\mathrm{D}$ on serum calcium in rats. Acta physiol. scand. 1964, 62, 391. 